\title{
Follicular Cell-Derived Thyroid Cancer in Children
}

\author{
Sophie Leboulleux Eric Baudin Dana W. Hartl Jean-Paul Travagli \\ Martin Schlumberger
}

Institut Gustave Roussy, Villejuif, France

\section{Key Words}

Thyroid cancer $\cdot$ Children

\begin{abstract}
Thyroid carcinoma is a rare disease in chidhood. The only known causative factor is radiation exposure during childhood. Most cases can be cured by surgery and eventually radioiodine. The aim of initial treatment should be the total removal of neoplastic foci with a minimal morbidity. Some cancer-related deaths have been reported decades after initial treatment.
\end{abstract}

Copyright (c) 2005 S. Karger AG, Basel

\section{Introduction}

In children, most thyroid carcinomas are derived from follicular cells [1-3]. Medullary thyroid carcinomas derived from parafollicular cells (or C cells) are rare and beyond the scope of this review.

\section{Incidence}

Thyroid cancer is a rare disease in children, accounting for 1.5 to $3 \%$ of all childhood cancers in North America and Europe, with an annual incidence of 0.5 to 1 case per million children [4]. Its incidence is similar between series. It is exceptional before the age of 10 years, and its incidence increases from then on. The sex ratio $(F / M)$ is close to unity before puberty, and reaches $2.5-6.0$ to 1 after puberty.

\section{Pathology}

In children, the vast majority ( $>90 \%)$ of follicular cellderived thyroid carcinomas are papillary (PTC). In very young children, papillary carcinoma variants such as the diffuse sclerosing and the follicular variants develop more frequently, and a solid/follicular growth pattern is frequently observed.

As compared to adult papillary carcinomas, large size of the thyroid tumor, multifocality and bilaterality, extension beyond the thyroid capsule, neck lymph node metastases (present in up to $80 \%$ of the cases, frequently large with extension beyond the capsule) and lung metastases (present in 10-20\% of the cases) are more frequently observed in children [5-9]. This severe presentation, particularly in young children, may be related to a late diagnosis or to an aggressive course (table 1).

\section{Etiology}

Epidemiological studies have shown that the thyroid gland is one of the most sensitive organs to the tumorigenic effects of external radiation during childhood [10]. This was confirmed by the increased incidence of thyroid

\section{KARGER}

Fax +4161306 1234 E-Mail karger@karger.ch www.karger.com

\section{(C) 2005 S. Karger AG, Basel}

0301-0163/05/0633-0145\$22.00/0

Accessible online at:

www.karger.com/hre
Prof. Martin Schlumberger

Institut Gustave Roussy

FR-94805 Villejuif (France)

Tel. +33142116095, Fax +33142116363, E-Mail schlumbg@igr.fr 
Table 1. Characteristics of follicular cell-derived thyroid carcinoma in children and adults

\begin{tabular}{lll}
\hline Characteristics & Children & Adults \\
\hline Histology & $\begin{array}{l}\text { papillary }>90 \% \\
\text { variants: diffuse }\end{array}$ & papillary $70 \%$ \\
& sclerosing, follicular & \\
Tumor & large, multiple & \\
Lymph nodes & $60-80 \%$ & $25-40 \%$ \\
Distant metastases & $10-20 \%$ & $<5 \%$ \\
${ }^{131}$ I uptake & $>80 \%$ & $60 \%$ \\
Recurrence rate & $>25 \%$ & $2-25 \% *$ \\
Mortality & $<5 \%$ & $<2-40 \% *$ \\
\hline
\end{tabular}

* Depend on the initial prognostic indicators (TNM).

Table 2. Frequency (\%) of oncogenes activated in papillary thyroid carcinoma in children and adults

\begin{tabular}{lcc}
\hline & $\begin{array}{l}\text { Sporadic } \\
\text { (adults) }\end{array}$ & $\begin{array}{l}\text { Radiation- } \\
\text { induced } \\
\text { (children) }\end{array}$ \\
\hline RET/PRC & $5-30$ & $30-70$ \\
RAS & $<10$ & $<10$ \\
BRAF & $35-60$ & $<10$ \\
TRK & $<10$ & $<10$
\end{tabular}

carcinoma in highly contaminated children in Belarus and Ukraine after the Chernobyl nuclear disaster, and this was attributed to the contamination by radioactive isotopes of iodine [7, 8]. Among nodules occurring in subjects with a history of radiation exposure during childhood, about $20-30 \%$ are malignant, the large majority being papillary cancers, and the other nodules are benign adenomas. The sensitivity of the thyroid gland to the carcinogenetic effects of radiation is maximal during the first years of life and then decreases with increasing age at exposure. The risk is not significant for exposure at an age above $15-20$ years. The risk is significant for radiation doses to the thyroid as low as $100 \mathrm{mGy}$ and for higher doses it increases linearly with the dose. The excess relative risk is high. For $1 \mathrm{~Gy}$ delivered during the first years of life it is equal to 7.7 , and more than $80 \%$ of thyroid carcinomas occurring in these subjects can be attributed to radiation exposure. There is a 5- to 10-year period after radiation exposure before nodules start to appear. The incidence peaks at 15-19 years and then declines but re- mains elevated for at least 20 years. The prognosis of childhood thyroid cancer and response to therapy are similar in spontaneously occurring and in radiation-induced papillary carcinomas and is in general favorable $[11,12]$. The aggressiveness of thyroid carcinomas observed in heavily exposed children a few years following the accident of Chernobyl may be related to the type of radiation exposure, to late diagnosis or incorrect treatment, to the young age at occurrence or to other yet undetermined factors. In Western countries, there is no significant increase in the incidence of thyroid carcinoma in children since the Chernobyl accident.

In approximately $5 \%$ of children, there is a family history of papillary thyroid carcinoma. This may occur in families with adenomatous polyposis or Cowden's disease. In other families, there are no associated lesions and linkage studies have permitted chromosomal mapping of at least three syndromes [13].

\section{Genetics}

Several genetic defects have been shown in childhood papillary thyroid carcinoma, including RET/PTC rearrangements and, rarely, activating point mutations in the signal transducing pathway (in RAS and B-RAF genes) [14] (table 2).

Of particular interest is the finding of RET/PTC rearrangement in 30 to more than $70 \%$ of childhood PTC occurring after exposure to external radiation or after internal contamination following the Chernobyl accident. RET/PTC3 rearrangements are associated with aggressive tumors and RET/PTC1 rearrangements with classical PTC. Also, a high frequency of RET/PTC rearrangement was reported in childhood PTC occurring in the absence of radiation exposure. This contrasts with a lower frequency (5-30\%) of RET/PTC rearrangement and a higher frequency of B-RAF mutation ( $40 \%$ in adults versus less than $10 \%$ in children) found in adult PTC occurring in the absence of radiation exposure. This suggests that radiation exposure induces double strand breaks that will lead to RET/PTC rearrangements in children in the absence of effective repair mechanisms.

\section{Prognosis}

Age at diagnosis and extent of disease are the most significant prognostic factors for thyroid cancer. In the TNM classification, pediatric thyroid cancer without dis- 
Fig. 1. Papillary carcinoma. a Papillary structures consisting in a conjunctivo-vascular core bordered by papillary cells. $\times 200$. b Papillary cells; note their typical appearance (large size, overlap, hypodense chromatin (ground glass), irregular borders, fissure, cytoplasmic invagination). These nuclear features permit the diagnosis of papillary carcinoma on cytology. $\times 400$. c Cytology obtained by fine-needle biopsy of a papillary carcinoma. $\times 400$.
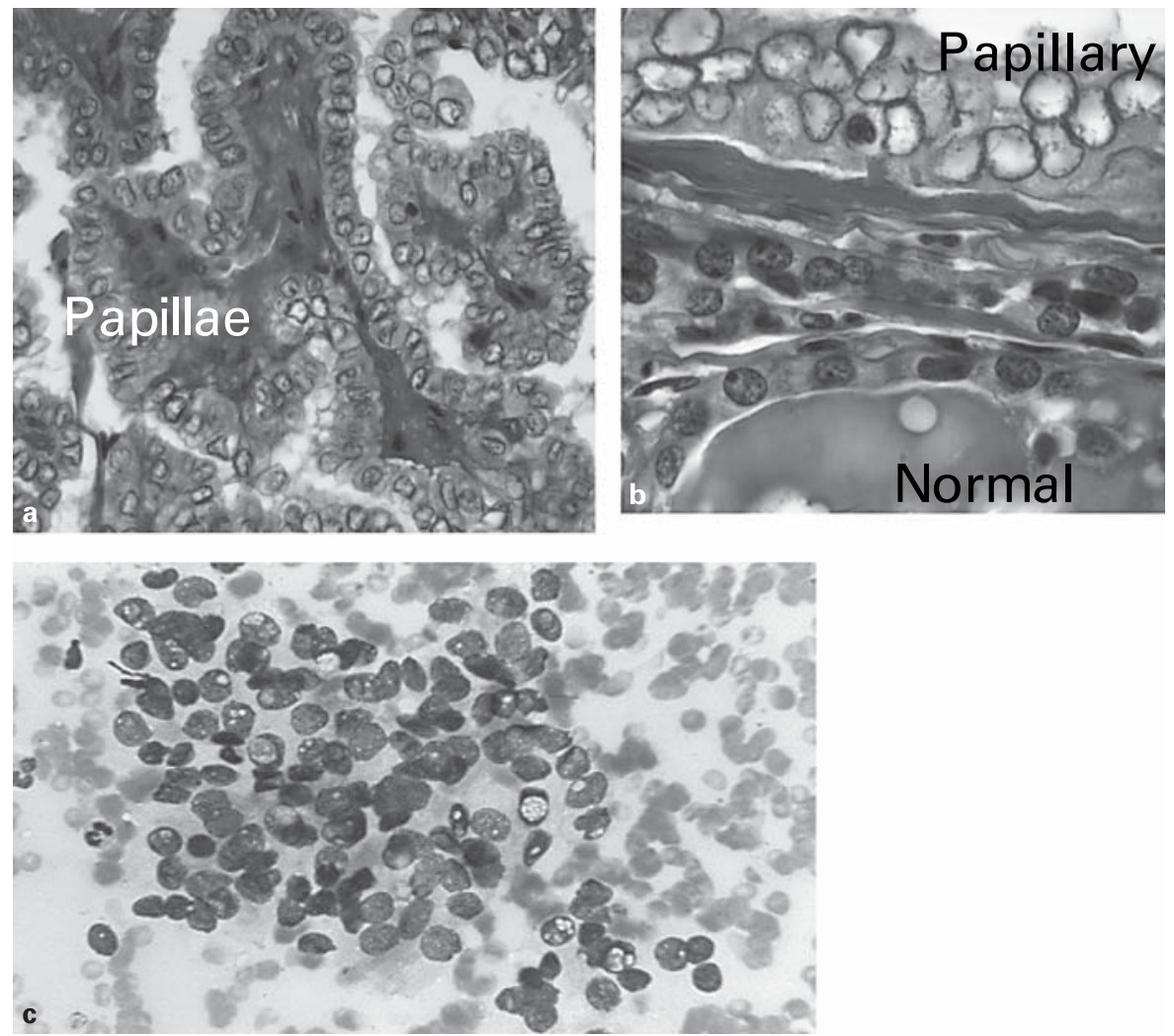

tant metastases is defined as stage I and when distant metastases are present it is defined as stage II [15]. This classification indicates that young patients are at a low risk of cancer-related death, despite frequently extensive disease at diagnosis, but underscores the risk of recurrence which is much higher than in adults. It should be noted than even if survival rates at 10 and 20 years are optimal, cancer-related deaths have been reported at an adult age, mostly in subjects who had been treated initially before the age of 10 years.

Papillary thyroid carcinoma is more aggressive when diagnosed before the age of 10 years [9]. In these younger children, a solid/follicular growth pattern, large tumor size, multifocality and extension beyond the thyroid capsule are frequent at presentation, as well as lymph-node involvement and lung metastases [16]. The recurrence rate was indeed higher than in older children and the cancer-related mortality was significantly increased, with death occurring at an adult age. In contrast, in older children and adolescents the initial extent of disease and outcome are similar to what is observed in young adults [1, $5-9,17-23]$. This is consistent with the high degree of tumor-cell differentiation: ${ }^{131} \mathrm{I}$ uptake is found in more than $80 \%$ of children with metastatic disease and ${ }^{131} \mathrm{I}$ concentration is frequently high in tumor tissue. Thus, ${ }^{131}$ I treatment will deliver high radiation doses and will yield a high cure rate. Among patients with distant metastases, younger age at the discovery of distant metastases is a significant independent prognostic factor for cure [16]. In some series no cancer-related-death was reported, but in series with the longest follow-up, up to $15 \%$ of cases died from their thyroid carcinoma [17-23].

\section{Clinical Presentation}

The clinical presentation of childhood thyroid cancer is mainly a thyroid nodule that is frequently large, either isolated or associated with neck lymph nodes. In some children, lymph nodes are present in the lower part of the neck without any detectable thyroid nodule, and in some children a diffuse hard goiter is present in the neck. Palpable thyroid nodules are more frequently malignant in children than in adults. Fine needle aspiration biopsy of either a thyroid nodule or of an enlarged neck lymph node with cytological analysis should confirm the diagnosis (fig. 1). 


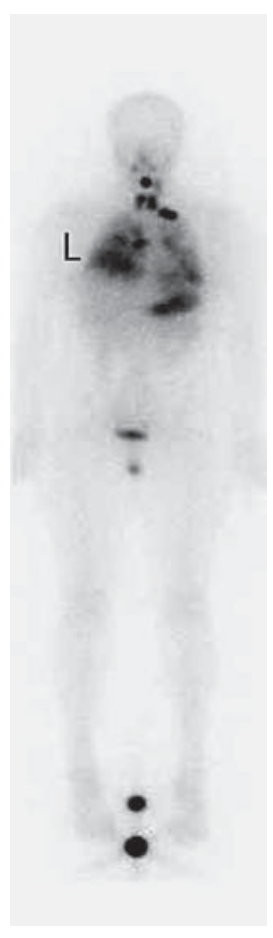

Fig. 2. Total body scan with radioiodine. Presence of small thyroid remnants in the thyroid bed, of lymph node metastases, and of diffuse lung metastases (L). The chest Xray was normal and the patient was cured with repeated radioiodine treatments.
Lung metastases are more frequently present than in adults. They are diffuse and micronodular, and may be not detected on standard chest X-rays and not even on spiral CT scan.

The clinical presentation of childhood thyroid cancer has been changing over the past decades [20]. The incidence of local tumor extension, palpable neck lymph nodes and lung metastases has decreased. This probably reflects greater attention paid by pediatricians to routine examination of the thyroid gland.

\section{Treatment}

Treatment is based on surgery, radioiodine and thyroid hormone therapy. There is no role for external radiation therapy or chemotherapy.

\section{Surgery and Radioiodine Therapy}

The initial treatment for all thyroid cancers is surgery. As the extent of papillary thyroid carcinoma in children is frequently multifocal and bilateral, a total thyroidectomy is warranted. However, on the basis of the favorable out- come of most papillary thyroid carcinomas, some authors advocated less aggressive treatment in order to decrease the risk of morbidity [21], but there is then a major risk of under-treatment. Likewise, as lymph node metastases are frequently present and may be large, routine lymph node dissection is justified. 'En bloc dissection' is the only recommended procedure. Dissection of the central neck compartment (level VI) is routinely performed and may be extended to the supra-clavicular area. When involved, the antero-superior mediastinum should also be carefully dissected. When a jugulo-carotid metastasis is present, a modified jugulo-carotid lymph node dissection preserving the sterno-cleido-mastoid muscle, the spinal accessory nerve and the internal jugular vein is carried out.

Moreover, in children and adolescents, most lung metastases are not visible on chest X-rays or on CT scan, and are only evidenced on ${ }^{131}$ I total body scan performed after thyroid ablation (fig. 2). In patients who were not submitted to radical initial surgery, serum thyroglobulin $(\mathrm{Tg})$ measurement is less specific, and ${ }^{131} \mathrm{I}$ imaging is less sensitive. In consequence, metastases may remain silent for years and emerge with a greater tumor burden. For these reasons, most clinicians favor a total thyroidectomy and lymph-node dissection, and ${ }^{131}$ I therapy in cases with extensive disease.

The ablative dose of ${ }^{131} \mathrm{I}$ in children is approximately $37 \mathrm{MBq} / \mathrm{kg}(1 \mathrm{mCi} / \mathrm{kg})$ body weight. When only a lobectomy or a partial thyroidectomy has been performed, a completion thyroidectomy may be indicated, according to the size of the remnants and the risk of persistent disease. When performed, it should be associated with a lymph node dissection, according to the protocol of initial surgery.

This combined treatment is probably the only currently available method to decrease the risk of local and regional recurrence and to achieve a cure [1].

\section{Hormonal Therapy}

Following thyroidectomy, the treatment of choice is $L$-thyroxine (L-T4). Compared to adult subjects, children require higher doses per $\mathrm{kg}$ of body weight to decrease $\mathrm{TSH}$ level below $0.1 \mu \mathrm{U} / \mathrm{ml}$ (that is considered adequate to suppress TSH-dependent tumor growth), with normal FT3 and FT4 values (that will avoid an iatrogenic thyrotoxicosis). Thus, a child below the age of 10 years may require an L-T4 dose of 3-4 $\mu \mathrm{g} / \mathrm{kg} / \mathrm{day}$, and at the age of $16-18$ years a daily dose of $2.4-2.8 \mu \mathrm{g} / \mathrm{kg}$ may be sufficient. 
Serum TSH and FT3, FT4 levels are measured 3 months after initiation of therapy and then at least every 6 months. Growth rate is normal with the expected adult height being reached at a normal age, puberty occurs normally, and no permanent side effects on the heart or the skeleton were observed at an adult age.

Of course, TSH suppressive therapy is not mandatory for all children. In the majority of patients who appear to be in complete remission, the daily dose of L-T4 may be decreased to achieve a TSH level in the normal range (around $0.5 \mu \mathrm{U} / \mathrm{ml}$ ).

\section{Diagnosis and Treatment of Persistent and Recurrent Disease}

The search for persistent disease includes a ${ }^{131}$ I total body scan performed 3-5 days after the administration of the large dose given to ablate thyroid remnants. Any uptake focus outside the thyroid bed, in lymph node areas or in lungs is related to metastatic spread and should be treated. Then, L-T4 treatment is initiated and serum Tg determination is obtained 3 months later without discontinuation of L-T4 treatment. Serum Tg is obtained again 6-9 months later following TSH stimulation, and neck ultrasonography is performed [24] (fig. 3). Prolonged withdrawal of thyroid hormone treatment is often poorly tolerated by children, and for this reason the use of rhTSH may be particularly beneficial. When no abnormalities are found (undetectable serum Tg following TSH stimulation and normal neck ultrasonography), L-T4 treatment dose can be decreased and serum Tg determination during L-T4 treatment and neck ultrasonography are obtained every year [2, 25] (fig. 4).

Neck lymph node metastases may be present in patients with undetectable serum Tg levels during L-T4 treatment. Neck palpation is not sensitive enough and lymph nodes are often discovered at routine neck ultrasonography and diagnosed at fine needle biopsy with cytology and Tg measurement in the fluid aspirate. The discovery of lymph node metastases should lead to a complete work-up and treatment, starting with the administration of a large activity of ${ }^{131}$ I with a total body scan 3 days later that will localize lymph node metastases and identify distant metastases. Surgery is then undertaken with the use of an intra-operative probe. The extent of surgical excision will depend on the extent of recurrent disease and on the protocol of primary surgery. Using this protocol, complete resection of neoplastic foci was obtained in more than $90 \%$ of patients [26].

Follicular Cell-Derived Thyroid Cancer in Children

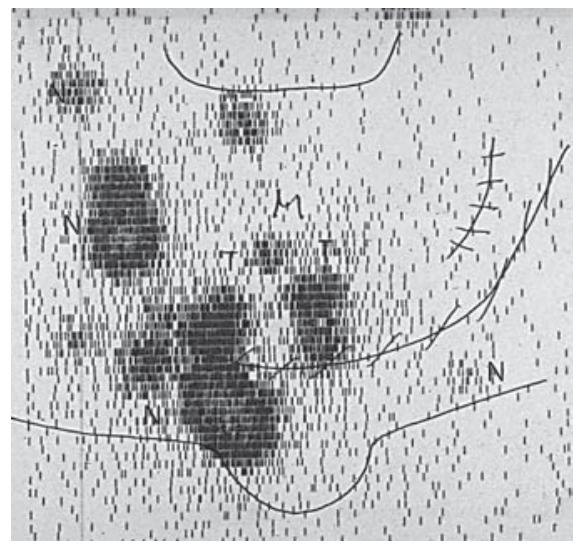

Fig. 3. Neck scintigraphy with radioiodine that shows normal thyroid remnants $(\mathrm{T})$ in the thyroid bed and uptake in lymph node metastases $(\mathrm{N})$.

In patients with lung metastases, treatment is based on ${ }^{131} \mathrm{I}(37 \mathrm{MBq}(1 \mathrm{mCi}) / \mathrm{kg}$ body weight $)$ with a TBS performed 3-5 days after the dose. This is repeated every 6 months until the disappearance of any uptake on posttherapy TBS. Cure is obtained after 4 to 6 courses of ${ }^{131} \mathrm{I}$ treatment in more than $80 \%$ of children with ${ }^{131}$ I uptake. The other rare children with lung metastases do not achieve a cure, and this can be related to an incorrect use of ${ }^{131} \mathrm{I}$ or an insufficient ${ }^{131} \mathrm{I}$ uptake in the metastases. Growth rate of metastases is usually very slow on L-T4 suppressive therapy, but due to the long life-expectancy persistent disease may cause death several decades after initial treatment.

Children with lung metastases often show large mediastinal lymph nodes: lung metastases can be treated with ${ }^{131} \mathrm{I}$ and cure is frequently achieved, but large lymph nodes may require surgical resection following several treatments with ${ }^{131} \mathrm{I}$; this may decrease their size and facilitate their resection.

Finally, few children with lung metastases may develop bone or brain metastases that may require surgery, external radiation therapy and ${ }^{131} \mathrm{I}$ treatment when uptake is present.

\section{Treatment-Related Morbidity}

Treatment-related morbidity is particularly relevant for the developing body of a child whose life-expectancy is long. In expert hands, the risk of laryngeal nerve palsy 

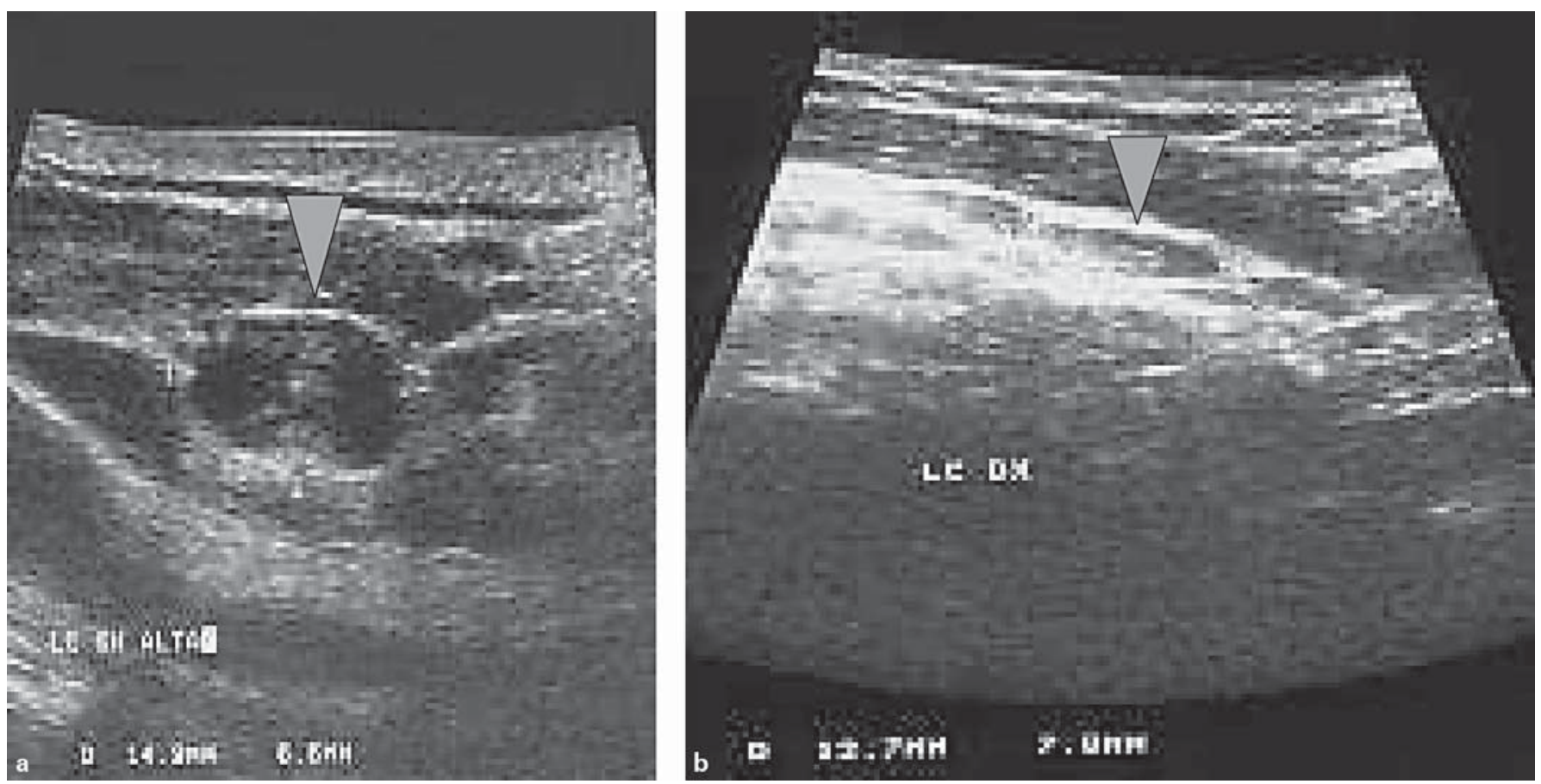

Fig. 4. Neck ultrasonography. Suspicious lymph node that is round, hypoechoic without central echo (a) and benign lymph node (b).

and of permanent hypoparathyroidism after total thyroidectomy with lymph node dissection is minimal and similar to that reported in adult patients. The likelihood of surgical complications is increased during central neck dissection and at reoperation, but should not tip the balance towards conservative surgery. Rather, it underscores the absolute need to refer the young patient to a surgeon who has expertise in the field.

The risk of laryngeal nerve palsy is transient in the majority of cases. However, nerve resection may be necessary when the nerve is involved in a tumoral mass.

The risk of permanent hypoparathyroidism may be decreased by localization of the parathyroid glands with methylene-blue staining and auto-transplantation in a muscle. The clinical features of hypocalcemia are severe in children and include anxiety, paresthesia, carpopedal spasm and in extreme cases laryngospasm and convulsions. It should be promptly treated. Measuring serum ionized calcium and circulating parathyroid hormone (PTH 1-84) is the simplest way to monitor the recovery of parathyroid gland function or to document permanent hypoparathyroidism. The goal of medical therapy is to render the patient asymptomatic and to stabilize the serum calcium level in the lower part of the normal range.
Serum calcium levels in the upper part of the normal range expose the patient to chronic hypercalciuria, with the risk of renal complications. Both calcium (1.5-2.5 g per day) and vitamin D analogs are needed. Vitamin D analogs to be administered are calcitriol (1,25-(OH)2D3), at a daily dose of $0.5-2.0 \mu \mathrm{g}$, or alfacalcidol (1-OHD3) at a daily dose of 1.0-3.0 $\mu \mathrm{g}$. Blood calcium levels are monitored once a week at the beginning of therapy, and once every 3-4 months thereafter with determination of calcium and creatinine on a casual urine sample.

The risk of pulmonary fibrosis can be avoided when ${ }^{131} \mathrm{I}$ activity is limited to about $37 \mathrm{MBq}(1 \mathrm{mCi}) / \mathrm{kg}$ body weight per treatment and with at least 6-month intervals between two courses.

The occurrence of second malignancies has never been addressed specifically in childhood thyroid cancer. In adult series, a significant increased incidence of second cancers and leukemias is observed in patients treated with high cumulative doses of ${ }^{131}$ I after several treatment courses for distant metastases, the relationship between the cumulative activity administered and the risk of second tumors being linear [27]. Such a risk underlines that ${ }^{131}$ I should be used only in children in whom it may be beneficial. 
Decreased fertility or infertility has been reported in male patients after high cumulative doses of ${ }^{131} \mathrm{I}$ [28]. This complication is particularly important in young patients who have an otherwise excellent life-expectancy and sperm preservation may be recommended. This is particularly true in patients with lung metastases after puberty as they may require several treatments with ${ }^{131} \mathrm{I}$. On the other hand, the outcome of pregnancies was not altered in women previously exposed to radioiodine [29].

\section{Conclusion}

Despite favorable long-term survival, pediatric follicular cell-derived thyroid cancer should be considered as a potentially lethal disease to be treated with radical surgery (total thyroidectomy and lymph-node dissection) and by radioiodine in cases with extensive disease, followed by $L$-thyroxine therapy. This will ensure definitive cure and a normal quality of life for most young patients with papillary thyroid carcinoma.

\section{References}

1 Hung W, Sarlis NJ: Current controversies in the management of pediatric patients with well-differentiated nonmedullary thyroid cancer: A review. Thyroid 2002; 12:683-702

$\checkmark 2$ Schlumberger MJ: Papillary and follicular thyroid carcinoma. N Engl J Med 1998;338:297_ 306.

3 Schlumberger MJ, Filetti S, Hay ID: Non toxic goiter and thyroid neoplasia; in Larsen RP, Kronenberg HM, Melmed S, Polonsky KS (eds): Williams' Textbook of Endocrinology, ed 10. Philadelphia, Saunders, 2002, pp 457490.

4 Greenlee RT, Hill-Harmon MB, Murray T, Thun M: Cancer statistics, 2001. CA Cancer J Clin 2001;51:15-36.

$\checkmark 5$ Harach HR, Williams ED: Childhood thyroid cancer in England and Wales. Br J Cancer 1995;72:777-783

6 Farahati J, Bucsky P, Parlowsky T, Mäder U, Reiners C: Characteristics of differentiated thyroid carcinoma in children and adolescents with respect to age, gender, and histology. Cancer 1997;80:2156-2162.

7 Pacini F, Vorontsova T, Demidchik EP, Molinaro E, Agate L, Romei C, Shavrova E, Cherstvoy ED, Ivashkevitch Y, Kuchinskaya E, Schlumberger M, Ronga G, Filesi M, Pinchera A: Post-Chernobyl thyroid carcinoma in Belarus children and adolescents: Comparison with naturally occurring thyroid carcinoma in Italy and France. J Clin Endocrinol Metab 1997;82:3563-3569.

8 Reiners C, Biko J, Demidchik YE, Drozd VM: Results of radioiodine treatment in children from Belarus with advanced stages of thyroid cancer after the Chernobyl accident; in: 'Chernobyl: Message for the 21st Century'. Excerpta Medica International Congress series 1234. Amsterdam, Elsevier, 2002, pp 69-75.

$\checkmark 9$ Schlumberger M, De Vathaire F, Travagli JP, Vassal G, Lemerle J, Parmentier C, Tubiana $\mathrm{M}$ : Differentiated thyroid carcinoma in childhood: Long-term follow-up of 72 patients. J Clin Endocrinol Metab 1987;65:1088-1094.

$\checkmark 10$ Ron E, Lubin JH, Shore RE, Mabuchi K, Modan B, Pottern LM, Schneider AB, Tucker MA, Boice JD: Thyroid cancer after exposure to external radiation: A pooled analysis of seven studies. Radiat Res 1995;141:259-277.
11 Rubino C, Cailleux AF, Abbas M, Diallo I, Shams aldin A, Caillou B, De Vathaire F, Schlumberger M: Characteristics of follicular cellderived thyroid carcinomas occurring after external radiation exposure: Results of a case control study nested in a cohort. Thyroid 2002; 12:299-304.

12 Viswanathan K, Gierlowski TC, Schneider AB: Childhood thyroid cancer. Characteristics and long-term outcome in children irradiated for benign conditions of the head and neck. Arch Pediatr Adolesc Med 1994;148:260265.

13 Malchoff CD, Malchoff DM: The genetics of hereditary nonmedullary thyroid carcinoma. J Clin Endocrinol Metab 2002;87:2455-2459.

14 Nikiforova M, Kimura ET, Gandhi M, Biddinger PW, Knauf JA, Basolo F, Zhu Z, Giannini R, Salvatore G, Fusco A, Santoro M, Fagin JA, Nikiforov YE: BRAF mutations in thyroid tumors are restricted to papillary carcinomas and anaplastic or poorly differentiated carcinomas arising from papillary carcinomas. J Clin Endocrinol Metab 2003;88: 5399-5404.

15 American Joint Committee on Cancer: Chapter 8: Thyroid; in: AJCC Cancer Staging Handbook, ed 6. New York, Springer, 2002, pp 8998.

16 Schlumberger M, Challeton C, De Vathaire F, Travagli JP, Gardet P, Lumbroso JD, Francese C, Fontaine F, Ricard M, Parmentier C: Radioactive iodine treatment and external radiotherapy for lung and bone metastases from thyroid carcinoma. J Nucl Med 1996;37: 598-605.

17 Ceccarelli C, Pacini F, Lippi F, Elisei R, Arganini M, Miccoli P, Pinchera A: Thyroid cancer in children and adolescents. Surgery 1988;104: 1143-1148.

18 Dottorini ME, Vignati A, Mazzucchelli L, Lomuscio G, Colombo L: Differentiated thyroid carcinoma in children and adolescents: A $37-$ year experience in 85 patients. J Nucl Med 1997;38:669-675.

19 Giuffrida C, Scollo C, Pellegriti G, Lavenia G, Iurato MP, Pezzino V, Belfiore A: Differentiated thyroid cancer in children and adolescents. J Endocrinol Invest 2002;25:18-24

20 Harness JK, Thompson NW, McLeod MK, Pasieka JL, Fukuuchi A: Differentiated thyroid carcinoma in children and adolescents. World J Surg 1992; 16:547-554.
21 La Quaglia MP, Corbally MT, Heller G, Exelby PR, Brennan MF: Recurrence and morbidity in differentiated thyroid carcinoma in children. Surgery 1988;104:1149-1156.

22 Newman KD, Black T, Heller G, Azizkhan RG, Holcomb GW, Sklar C, Vlamis V, Haase GM, La Quaglia MP: Differentiated thyroid cancer: determinants of disease progression in patients $<21$ years of age at diagnosis. Ann Surg 1998;227:533-541.

$>23$ Zimmerman D, Hay ID, Gough IR, Goellner JR, Ryan JJ, Grant CS, McConahey WM: Papillary thyroid carcinoma in children and adults: Long-term follow-up of 1039 patients conservatively treated at one institution during three decades. Surgery 1988;104:1157-1166.

24 Antonelli A, Miccoli P, Fallahi P, Grosso M, Nesti C, Spinelli C, Ferrannini E: Role of neck ultrasonography in the follow-up of children operated on for thyroid papillary cancer. Thyroid 2003;13:469-484.

25 Schlumberger M, Berg G, Cohen O, Duntas L, Jamar F, Jarzab B, Limbert E, Lind P, Pacini F, Reiners C, Sanchez Franco F, Toft A, Wiersinga WM: Follow-up of low-risk patients with differentiated thyroid carcinoma: A European perspective. Eur J Endocrinol 2004;50: 105-112.

26 Travagli JP, Cailleux AF, Ricard M, Baudin E, Caillou B, Parmentier C, Schlumberger M: Combination of radio-iodine $\left({ }^{131} \mathrm{I}\right)$ and probeguided surgery for persistent or recurrent thyroid carcinoma. J Clin Endocrinol Metab 1998;83:2675-2680.

-27 Rubino C, De Vathaire F, Dottorini ME, Hall P, Schvartz C, Couette JE, Dondon MG, Abbas MT, Langlois C, Schlumberger M: Second primary malignancies in thyroid cancer patients. Br J Cancer 2003;89:1638-1644.

28 Pacini F, Gasperi M, Fugazzola L, Ceccarelli C, Lippi F, Centoni R, Martino E, Pinchera A: Testicular function in patients with differentiated thyroid carcinoma treated with radioiodine. J Nucl Med 1994;35:1418-1422.

29 Schlumberger M, De Vathaire F, Ceccarelli C, Delisle MJ, Francese C, Couette JE, Pinchera A, Parmentier C: Exposure to radioactive iodine-131 for scintigraphy or therapy does not preclude pregnancy in thyroid cancer patients. J Nucl Med 1996;37:606-612. 